\title{
A Study on the Influence of Life Events and Coping Style on Psychological Capital of Senior Middle School Students
}

\author{
Fang $\mathrm{Bi}_{-j i^{1,}}{ }^{*}$, Liu Cai-xia ${ }^{2, b}$ \\ 1Department of Psychology, Gannan Medical University, Ganzhou, Jiangxi, China \\ ${ }^{2}$ Library of Gannan Medical University, Ganzhou, Jiangxi, China \\ ae-mail: xgfbj@126.com, be-mail: 82477534@qq.com, ”corresponding author
}

Keywords: life events; coping style; psychological capital

\begin{abstract}
To explore the influence of life events and coping style on psychological capital of senior middle school students, and provide an empirical basis for the work of senior middle school students' mental health education. With random sampling, 612 senior middle school students from six schools were surveyed with Adolescent Self-Rating Life Events Check List (ASLEC), Simplified Coping Style Questionnaire (SCSQ) and Psychological Capital Questionnaire for Adolescent Students (PCQAS). The data were analyzed by SPSS 17.0. There is significant correlation among the scores of 612 senior middle school students in ASLEC, SCSQ and PCQAS ( $<<0.01)$. The four factors (Interpersonal Relationships, Study Pressure, Loss and Others) of ASLEC can significantly predict senior middle school students' psychological capital $(\mathrm{F}=15.742, \mathrm{P}<0.01)$. Coping style plays the role of mediating variable in the prediction of life events on senior middle school students' psychological capital. Life events can significantly predict senior middle school students' psychological capital, and coping style plays the role of mediating variable in the prediction of life events on senior middle school students' psychological capital.
\end{abstract}

\section{Introduction}

Psychological capital (also called positive psychological capital), which can promote one's psychological development and boost one's behavioral performance, is a kind of positive mental potential showing in one's growth. Researches show that psychological capital has a great positive impact on the variables like job performance [1], subjective well-being [2], and mental health [3], etc. However, so far, there have been few researches on the affecting factors of psychological capital in academia.

Psychological capital, a kind of state-like positive mental potential, is affected by many factors. Not only the individual factors, but also the factors like companions, family, and society, etc can affect one's psychological capital. Researches suggest that adolescence is a period that physical development is imbalance with mental development. When the juveniles facing life events, the contradiction between quick physiological maturity and psychological developmental lag may make them be in stress easily. Because the psychological development of senior middle school students who spend most of the time in family and school is still in a state of half-maturity, stressful events will certainly bring immense effect to their mental healthy growth [4]. Psychological capital, a kind of positive mental potential showing in one's growth, will certainly be influenced by life events.

Researches indicate that the impact of life events on one's mental health is achieved through mediation of coping styles [5]. But we can't find the answers to the questions how the impact of life events plays on psychological capital and which role does the coping style play from the existent researches. So, it is necessary to study the influence of life events and coping style on psychological capital of senior middle school students so that we can explore the mechanism of the influence. 


\section{Methods}

Measures. Adolescent Self-Rating Life Events Check List (ASLEC). The questionnaire is composed of 6 subscales like Interpersonal Relationship, Study Pressure, Penalty, Loss, Healthy Adaptation, and Others, totally 27 negative life events which may cause psychological stress. The subjects are required to choose the rating of 1 to 5 according to the fact whether the events happened in the allotted time or not, and decide the impact of the events from "no-effect" to "severe-effect". If an event didn't happen, it will be rated as "no-effect". Researches show that the scale is of high reliability and fair validity [6].

Simplified Coping Style Questionnaire (SCSQ). The questionnaire is composed of 2 subscales like Positive Coping and Negative Coping, totally 20 items. The subjects are asked to give the rating from 0 to 3 according to the actual situation to each item. Researches show that the scale is of high reliability and fair validity [7].

Psychological Capital Questionnaire for Adolescent Students (PCQAS). The questionnaire is composed of 4 subscales like Hope, Optimism, Self-confidence, and Resilience, totally 22 items. The subjects are required to give the rating from 1 to 6 based on the fact. The more score the subject gets in the questionnaire, the higher level of psychological capital the subject has. Researches show that the questionnaire is of high reliability and fair validity [3].

Subjects. With random sampling, 660 senior middle school students from six schools were surveyed with ASLEC, SCSQ and PCQAS. In all, 660 copies were sent out in site, and were taken back on the spot. 612 valid copies (211 from Senior 1, 203 from senior 2, 198 from senior 3; 321 males, 291 females) are effective recovery ones through analysis.

Statistical Tool. The data are analyzed by SPSS for Windows 17.0.

\section{Results}

Correlation Analysis. The results of Pearson product-moment correlation analysis show that the scores in the subscales and total scale of PCQAS are negatively correlated with the scores in the subscales and total scale of ASLEC and the subscale of Negative Coping $(\mathrm{P}<0.01)$, and are positively correlated with the subscale of Positive Coping $(\mathrm{P}<0.01)$. The results also suggest that the scores in the subscales and total scale of ASLEC are negatively correlated with the scores in the subscale of Positive Coping $(\mathrm{P}<0.01)$, and are positively correlated with the subscale of Negative Coping $(\mathrm{P}<0.01)$.

Predictive Effect of Life Events on Senior Middle School Students' Psychological Capital. In this study, the multivariable linear regression is carried out by the method of Enter, the six subscales of ASLEC are independent variables, the total scale of PCQAS is dependent variable, and the demographic variables are control variables. The results are shown in Table 1.

Table 1 the Prediction of Life Events on Psychological Capital

\begin{tabular}{cccccccc}
\hline Independent Variables & $\beta$ & $\mathrm{t}$ & $\mathrm{Sig}$. & $\begin{array}{c}\text { Independent } \\
\text { Variables }\end{array}$ & $\beta$ & $\mathrm{t}$ & Sig. \\
\hline Interpersonal Relationship & -0.160 & $-2.051^{*}$ & 0.041 & Loss & 0.143 & $3.765^{* *}$ & 0.005 \\
Study Pressure & -0.338 & $-6.394^{* *}$ & 0.000 & Penalty & -0.069 & -1.418 & 0.161 \\
Healthy Adaptation & 0.081 & 1.479 & 0.143 & Others & -0.141 & $-3.732^{* *}$ & 0.006 \\
$\mathrm{~F}$ & & & & $15.742^{* *}$ & & & \\
$\mathrm{R}^{2}$ & & & & 0.263 & & & \\
Adjusted $\mathrm{R}^{2}$ & & & & 0.245 & & & \\
\hline
\end{tabular}

$*=\mathrm{P}<.05 ; * *=\mathrm{P}<.01$

From Table 1, we know that the four subscales like Interpersonal Relationship, Study Pressure, Loss and Others can significantly predict the senior middle school students' psychological capital when the effects of demographic variables are controlled. They could explain $24.5 \%$ of the total 
variance. While another two subscales like Healthy Adaptation and Penalty can't predict the senior middle school students' psychological capital.

Test for the Mediating Effect of Coping Style. The test for mediating effect of coping style is carried out based on the step and method given by Professor Wen [8]. The results are shown in Table 2 .

Table 2 Mediating Effect of Coping Style in Senior Middle School Students

\begin{tabular}{|c|c|c|c|c|c|}
\hline \multirow{2}{*}{\multicolumn{2}{|c|}{ Variables }} & \multirow{2}{*}{$\begin{array}{l}\text { Coefficient c } \\
\text { Psychological } \\
\text { Capital }\end{array}$} & \multicolumn{2}{|c|}{ Coefficient a } & \multirow{2}{*}{$\begin{array}{c}\text { Coefficient } \mathrm{c}^{\prime} / \mathrm{b} \\
\text { Psychological } \\
\text { Capital }\end{array}$} \\
\hline & & & Positive & Negative & \\
\hline \multirow[t]{4}{*}{$\begin{array}{l}\text { Independent } \\
\text { Variables }\end{array}$} & $\begin{array}{l}\text { Interpersonal } \\
\text { Relationship }\end{array}$ & $-0.160 * *$ & -0.028 & 0.048 & -0.081 \\
\hline & Study Pressure & $-0.338 * *$ & $-0.169 * *$ & $0.149 * *$ & $-0.219 * *$ \\
\hline & Loss & $0.143^{* *}$ & 0.049 & 0.031 & $0.121 * *$ \\
\hline & Others & $-0.141 * *$ & -0.116 & 0.079 & -0.068 \\
\hline \multirow{5}{*}{$\begin{array}{l}\text { Mediating } \\
\text { variables }\end{array}$} & Positive Coping & & & & $0.503 * *$ \\
\hline & Negative Coping & & & & $-0.211 * *$ \\
\hline & $\mathrm{R}^{2}$ & 0.263 & 0.082 & 0.106 & 0.473 \\
\hline & sted $\mathrm{R}^{2}$ & 0.245 & 0.065 & 0.089 & 0.461 \\
\hline & $\mathrm{F}$ & $15.742 * *$ & $5.342 * *$ & $6.208 * *$ & $38.972 * *$ \\
\hline
\end{tabular}

$* *=\mathrm{p}<.01$

The results in Table 2 indicate that all the regression coefficients c of Interpersonal Relationship, Study Pressure, Loss and Others to Psychological Capital reach significant level when the effects of demographic variables are controlled, the regression coefficients b of Positive Coping and Negative Coping to Psychological Capital also reach significant level. From Table 2, we also know that the regression coefficient a of Study Pressure to Positive Coping reaches significant level, which suggests that Positive Coping Style plays a mediating role in the prediction of Study Pressure on the senior middle school students' psychological capital. Further analysis shows that the regression coefficient $\mathrm{c}^{\prime}$ of Study Pressure to the senior middle school students' psychological capital is still significant after the mediating variable of Positive Coping Style is introduced. That is to say, Positive Coping Style plays part mediating role between Study Pressure and the senior middle school students' psychological capital. However, the regression coefficients a of Interpersonal Relationship, Loss and Others to Positive Coping Style aren't significant. The results of Sobel test [9] show that the mediating effect of Positive Coping Style in the prediction of the subscales like Interpersonal Relationship and Loss on the senior middle school students' psychological capital isn't significant $(\mathrm{Z}=-0.3497, \mathrm{P}>0.05 ; \mathrm{Z}=0.5415, \mathrm{P}>0.05)$. But the mediating effect of Positive Coping Style in the prediction of Others on the senior middle school students' psychological capital reaches significant $(\mathrm{Z}=-0.9316, \mathrm{P}<0.05)$. The test results find that the regression coefficient $\mathrm{c}^{\prime}$ of Others to the senior middle school students' psychological capital becomes unremarkable after the mediating variable of Positive Coping Style is introduced. That is to say, Positive Coping Style plays completely mediating role between Others and the senior middle school students' psychological capital.

The results also show that the regression coefficients a of Interpersonal Relationship, Loss and Others to Negative Coping Style aren't remarkable. The results of Sobel test show that the mediating effects of Negative Coping Style in the prediction of the subscales like Interpersonal Relationship, Loss and Others on the senior middle school students' psychological capital don't reach significant $(Z=-0.7204, P>0.05 ; Z=-0.3996, P>0.05 ; Z=-0.8299, P>0.05)$. But the regression coefficient a of Study Pressure to Negative Coping Style reaches remarkable, which suggests that Negative Coping Style plays an mediating role in the prediction of Study Pressure on the senior middle school students' psychological capital. Further analysis shows that the regression coefficient $\mathrm{c}^{\prime}$ of Study Pressure to the senior middle school students' psychological capital is still significant after the mediating variable of Negative Coping Style is introduced. That is to say, Negative Coping Style 
plays part mediating role between Study Pressure and the senior middle school students' psychological capital.

\section{Discussion}

The study finds that the subscales of Healthy Adaptation and Penalty have no prediction to the senior middle school students' psychological capital. There may be two reasons contributing to it. On the one hand, nowadays parents and schools pay much more attention to body-exercise and nutrition. In addition, modern medical service and the public awareness of preventing diseases are greatly improved. Thus, the students of senior middle school who can well understand and prevent the diseases have an increased resistance to most body diseases. So the factor of Healthy Adaptation has little influence on the normal development of their psychological capital. On the other hand, with the improvement of public educational level and popularization of quality education, people's ideas of education also changed a lot. In the course of modern family education and school education, more positive guidance and fewer penalties are brought to the students. So, the factor of Penalty also has no obvious impact on the normal development of senior middle school students' psychological capital.

The study shows that the subscales of Interpersonal Relationship, Study Pressure, Loss and Others can remarkably predict the senior middle school students' psychological capital. The prediction of the subscales of Interpersonal Relationship and Loss to the senior middle school students' psychological capital occurs directly. The factor of Interpersonal Relationship mainly refers to the negative events in interpersonal action, which can bring great effects to one's emotion, life, study and work because man is a social animal. The senior middle school students, who are just in psychological rebellious stage, long for acceptance and respect, and hope to find the bosom friend and friendly harmonious interpersonal relationship. So some negative events of interpersonal relationship can directly affect the senior middle school students' psychological capital. The factor of Loss mainly refers to the events of crisis or loss in property, kith and kin. When one experiences the events of crisis or loss, his mind may get great ups and downs, which may affect his mental health. But after one experienced such things, his cognition to the outside world may gradually trend rationality and objectivity. Thus his half-maturing mind may gradually trend maturity, just as the saying goes "eat a cutting wisdom". So their positive mental potential may be motivated instead when senior middle school students experience the crisis and loss in property, kith and kin, which will greatly improve their psychological capital.

The study indicates that the subscale of Study Pressure can partly predict the senior middle school students' psychological capital by the mediating variables of positive coping style and negative coping style. Senior middle school students whose task is mainly learning are just in critical and best time of study. Their academic achievements will affect the parents' and the teachers' assessments to them, which may directly influence their mental state. Positive assessment is helpful for them to realize their own positive mental potential and state. On the contrary, Negative assessment may breed harmful minds and bad feelings, which may suppress their positive mental potential. To get better academic achievements, senior middle school students are often under extreme study pressure. Facing study pressure, they would adopt different coping styles. The psychological capital will improve when positive coping style is adopted. So, learning guidance is very important in the process of mental health education to senior middle school students. Proper learning guidance can help one motivate his positive mental potential, enhance his psychological capital, and promote his mental health.

Moreover, the study also shows that the subscale of Others can completely predict the senior middle school students' psychological capital by the mediating variable of positive coping style. The factor of Others mainly refers to the life events like family economic problems, family conflicts and so on, which perhaps causes great impact to the normal development of one's mentality. Although this kind of life events may happen occasionally, the impact still can't be ignored to the inexperienced senior middle school students. Only when the students adopt positive coping style can they 
successfully get through the mental crisis so that the psychological capital can be improved effectively.

\section{Conclusion}

The four factors of Interpersonal Relationship, Study Pressure, Loss and Others can significantly predict the senior middle school students' psychological capital when the effects of demographic variables are controlled. The prediction of the factors like Interpersonal Relationship and Loss to the senior middle school students' psychological capital occurs directly. The factor of Others predicts the senior middle school students' psychological capital by the mediating variable of positive coping style. The factor of Study Pressure predicts the senior middle school students' psychological capital by the mediating variables of positive coping style and negative coping style.

\section{References}

[1] Avey, J. B., Reichard, R. J., Luthans, F., et al. Meta-analysis of the Impact of Positive Psychological Capital on Employee Attitudes, Behaviors, and Performance, Human Resource Development Quarterly, 2011, 22(2): 127-152.

[2] Shen Ji-liang, Fang Xiao-yi, Wang Jian-ping, et al, Disadvantaged Children's Psychological Development and Educational Countermeasures, Economic and Scientific Press House, Beijing, 2009.

[3] Fang Bi-ji, A Study on the Structure, Feature, Related Factors and Group Intervention of the Adolescent Students'Psychological Capital, Doctoral Paper of Fujian Normal University, 2012.

[4] Chen Yan, Jin Yue-long, Kang Yao-wen, et al, Relationship of Sub-health to Stressful Life Events and Coping Styles in Middle School Students, Chinese Mental Health Journal, 2012, 26(4): 257-261.

[5] Chen Yan, Kang Yao-wen, Yao Ying-shui, A Review on the Researches of Relationship among Life Events, Coping Style and Adolescent's Mental Health, Chinese Journal of School Health, 2012, 33(2): 254-256.

[6] Liu Xian-chen, Liu Lian-qi, Yang Jie, et al, A Study on the Reliability and Validity of Adolescent Self-Rating Life Events Check List, Chinese Journal of Clinical Psychology, 1997, 5(1): 34-36.

[7] Xie Ya-ning, A Preliminary Study on the Reliability and Validity of simplified coping style questionnaire, Chinese Journal of Clinical Psychology, 1998, 6(2): 114-115.

[8] Wen Zhong-lin, Chang Lei, Hau Kit-Tai,et al, Testing and Application of the Mediating Effects, Acta Psychologica Sinica, 2004, 36(5): 614-620.

[9] Sobel, M. E., Direct and Indirect Effects in Linear Structural Equation Models, In: J. S. Long (Ed.), Common Problems/Proper Solutions, Beverly Hills, CA: Sage, 1988: 46-64. 